\title{
ECONOMIA CRIATIVA: QUESTÕES SOBRE O PROCESSO CRIATIVO
}

\author{
CREATIVE ECONOMY: QUESTIONS ABOUT THE CREATIVE PROCESS \\ ECONOMÍA CREATIVA: PREGUNTAS SOBRE EL PROCESO CREATIVO
}

\author{
Cristiano Max Pereira Pinheiro \\ Doutor, Feevale \\ maxrs@feevale.br
}

\author{
Francisco Eduardo Menezes Martins \\ Doutor, Feevale \\ menezes@feevale.br
}

Mauricio Barth

Mestrando, Feevale mauricio@feevale.br

\begin{abstract}
Resumo
O ensaio aborda a emergente discussão no país sobre Economia Criativa sob a luz do processo criativo. Estabelece a relação entre conceitos de criatividade e o processo de valoração de ideias, gerando questionamentos ao formato consolidado de Economia Criativa e sua apropriação no Brasil. Consolidada há mais de 20 anos em países do exterior, como Inglaterra, Austrália, Canadá e EUA, o ensaio aponta como resultados um mapa conceitual sobre a criatividade e a reflexão sobre a produção de conteúdo de entretenimento como alternativa para o desenvolvimento da Economia Criativa no Brasil.
\end{abstract}

Palavras-chave: Criatividade. Economia Criativa. Processo Criativo.

\begin{abstract}
This essay focuses on the emerging debate in the country about the Creative Economy in the light of the creative process. Establishes the relationship between the concepts of creativity and the process of valuing ideas, raising questions to the consolidated format Creative Economy and its appropriation in Brazil. Consolidated more than 20 years in foreign countries, such as England, Australia, Canada and USA, the test results shows how a concept map on creativity and reflection on the production of entertainment content as an alternative to the development of the Creative Economy in Brazil.
\end{abstract}

Key words: Creativity. Creative Economy. Creative Process.

\section{Resumen}

Este ensayo se centra en el debate emergente en el país de Economía Creativa, a la luz del proceso creativo. Establece la relación entre los conceptos de la creatividad y el proceso de valoración de las ideas, lo que plantea preguntas el formato consolidado de Economía Creativa y su apropiación en Brasil. Consolidado por más de 20 años en los países extranjeros, como Inglaterra, Australia, Canadá y EE.UU., los puntos de prueba como resultados un mapa conceptual en la creatividad y la reflexión sobre la producción de contenidos de entretenimiento como una alternativa para el desarrollo de la Economía Creativa en Brasil.

Palabras clave: Creatividad. Economía Creativa. Proceso Creativo. 


\section{INTRODUÇÃO}

A Economia Criativa movimenta cifras enormes de dinheiro no mundo. Esses valores mudam mês a mês dada a potência e as oportunidades que esse campo apresenta. De acordo com Jonh Howkins em Creative Economy: How people make money from Ideas, existem 15 setores de economia criativa: Publicidade, Arquitetura, Arte, Artesanato, Design, Moda, Cinema, Música, Artes Performáticas (Dança, Teatro, Ópera e Ballet), Publicação, Pesquisa e Desenvolvido (P\&D), Software, Brinquedos e Jogos (excluindo videogame), Rádio e TV, e Videogames.

Diversos países começam a traçar e atualizar políticas sobre como incentivar a produção dos conteúdos da economia criativa de forma a criar propriedade intelectual (DCA, 1994; DCMS, 1998; MINC, 2011; SEI, 2013), gerando, assim, uma série de benefícios nacionais como aumento do PIB, posicionamento internacional com base em tecnologia ou conteúdos de entretenimento. Mesmo com esse cenário que aponta um crescimento prolongado nos próximos anos, e com centenas de artigos e publicações que apontam números de cada setor da indústria em diferentes países, ainda assim existem problemas processuais interessantes.

Neste ensaio, apresentamos uma proposta de buscar as origens, trajetórias e transfigurações do conceito de criatividade, além de propor a discussão sobre o papel do processo criativo dentro da Economia Criativa. No imaginário popular, Economia Criativa é criatividade, porém, é mais do que o processo de geração de ideias; é um sistema que abrange sua natureza multidisciplinar e necessita de outros processos agregadores para a valorização do que acreditamos ser, talvez, o principal ator: a criatividade.

\section{CRIATIVIDADE: UMA GENEALOGIA DO CONCEITO}

Entre a percepção de imagens e a criação de imaginários, é possível identificar e traçar algumas rotas já percorridas pelo conceito de criatividade. "A criação é a invenção de possibilidades na realidade" (MARINA, 1993, p. 21). Desde a antiga Grécia, a questão inspira a filosofia. Quais seriam as condições ideais para as mentes criadoras expressarem seu potencial? Em que momento um pensamento é convertido em ideia criativa?

A história helênica, por exemplo, registra a palavra Eureka! como a verbalização da criatividade, que surge como uma luz. Foi gritada por Arquimedes, enquanto corria pelas ruas 
de Siracusa, momentos depois de ter encontrado, durante o banho, a solução de como medir o volume de um objeto irregular, após vários dias de dedicação ao problema (BODEN, 1994).

Assim como o filósofo, outras pessoas criativas conseguiram seguir sua intuição de forma consciente, associar informações da memória e, instantaneamente, resolver um problema sobre o qual já dedicavam algum tempo. A história da ciência aponta um padrão semelhante: o avanço de uma teoria científica corresponde ao retrocesso do antropocentrismo, como nos casos de Copérnico, Darwin e Freud, que duvidaram do senso de suas épocas e propuseram rupturas científicas. "A criatividade humana, neste cenário, está acima da racionalidade" (BODEN, 1994, p. 353).

Bachelard, por sua vez, buscou um caminho inverso ao da filosofia clássica, no que concerne à imaginação reprodutora. Investiu na imaginação no sentido contrário ao da racionalidade: opôs-se aos dogmas e restrições e desenvolveu o conceito de imaginação criadora. "A autêntica viagem da imaginação é a viagem ao país do imaginário, ao seu domínio" (BACHELARD, 1993, p. 13). Para ele, a limitação da imaginação reprodutora da realidade, baseada na percepção de imagens, coisas e ideias, apontava para uma saída ao estilo do super-homem nietzschiano. Um sujeito portador da imaginação criadora estaria na condição de estabelecer novas realidades e de superar o homem comum pela potência do imaginário e não pelo poder das imagens. "Perceber e imaginar são como presença e ausência. Imaginar é ausentar-se, é lançar-se a uma vida nova” (BACHELARD, 1993, p. 12)

A noção anticartesiana e desalinhada dos ideais da modernidade aproxima o pensamento bachelardiano das análises de Jung sobre a imaginação, onde a imagem é a própria psique, ao mesmo tempo em que é sinônimo de realidade particular, onde a fantasia revela-se como concepção da própria atividade psíquica.

Conforme Jung (1991), a síntese entre a intensidade viva do real e sua respectiva elaboração intelectual é obra da imaginação. Esse fenômeno, que se dá incessantemente, é a manifestação da imaginação através de atos incessantes de criação. Ela comporta e liga todas as funções e os opostos como geradora de todas as possibilidades. Jung vê a imaginação criadora como elemento vivo de ligação e corrente de criação contínua.

De acordo com Bachelard (1993), desde o momento em que as imagens aparecem em série, descobrem uma matéria prima, um elemento fundamental: a fisiologia da imaginação, ainda mais que sua anatomia obedece a Lei dos Quatro Elementos (água, terra, fogo e ar). “Um elemento material é o princípio de um 'dom condutor' que dá continuidade a um psiquismo imaginante. Todo elemento que adota a imaginação material prepara uma 
sublimação especial e uma transcendência característica à imaginação dinâmica" (BACHELARD, 1993, p. 17).

A relação do imaginário com a matéria começa na própria criação de conceitos, no nível da psique, e se estende às aplicações exteriores e posteriores dos processos criativos. A filosofia dos quatro elementos sugere a passagem rumo a uma genealogia do imaginário da criatividade e conjuga com a sentença "a filosofia é a arte de criar conceitos" (DELEUZE, 1992), a compreensão das fontes e dos fluxos do pensamento ativo e da imaginação criadora.

\section{CRIATIVIDADE}

Muitos autores, entre eles José Predebon (2005) e Victor Mirshawka Júnior e Victor Mirshawka (2003), já definiram criatividade para uso em processos profissionais, porém, o assunto é complexo e diversas conceituações já foram estabelecidas, na sua maioria complementares para formação de uma Universalidade. Segundo Predebon, criatividade é “a competência de raciocinar construtivamente, pensando o novo/relevante" (2005, p. 45).

Ao criar algo, devemos analisar alguns pontos: já existe algo com a mesma função do que estou criando? Qual a diferença da minha invenção para o que já existe? No que será útil a minha ideia? É importante avaliar esses tópicos para saber se a ideia é realmente criativa ou apenas algo diferente do que já existe, mas com a mesma funcionalidade.

$\mathrm{O}$ ato criativo/questionador colocado por Predebon, apresenta a centelha inicial da reflexão acerca do registro de ideias, o que se tornará, mais adiante, um dos princípios organizativos da Economia Criativa. Já existe? Pertence a quem? O que fazemos agora? Criar é muito mais perguntar do que afirmar.

Uma boa ideia deve ser nova, ou seja, não ter sido pensada e colocada em prática ainda. Além disso, a ideia deve ser relevante, se destacando das outras ideias parecidas. Comumente, uma ideia nova surge de algo que todos julgavam impossível; um bom exemplo para isso é a ideia de que os homens podem se tornar invisíveis. Todos irão contra a afirmação até alguém encontrar uma forma de se tornar invisível. Isso é óbvio, mas o ato criativo se constitui de uma obviedade após seu lampejo, tornando, assim, espetacular a sensação e o prazer de quem cria a quem usufrui.

Ao contrário do que a maior parte da sociedade pensa, criatividade não é uma característica exclusiva de artistas. $\mathrm{O}$ ato de criar não se limita ao campo artístico, estando presente do desenho do arquiteto à administração de uma escola. Um exemplo de criatividade na prática utilizado por Predebon (2005) disserta sobre fabricantes de uma marca de creme 
dental que perceberam um problema em uma das máquinas no processo de embalagem. De vez em quando os tubos de creme saíam prontos e embalados, porém, sem o produto dentro. Diversos testes foram feitos, vários palpites foram dados, mas ninguém chegava a uma conclusão que acabasse de fato com o problema. Um dos trabalhadores da linha de produção que acompanhava de longe os trabalhos se aproximou e perguntou: "Por que não colocam um ventilador na saída da máquina para assoprar os tubos vazios?”. E assim foi resolvido o problema da empresa, com uma sugestão de alguém que assistia o problema de fora e não pensava analiticamente, em como consertar a máquina ou no número de tubos que saíam sem creme.

A criatividade, embora não percebida, está presente em todas as pessoas. Nascemos com a capacidade de criar, perguntar, inventar, imaginar e descobrir. Contudo, à medida que crescemos na sociedade, desaprendemos a usar toda nossa capacidade de pensar diferente e passamos a utilizar quase que exclusivamente o lado esquerdo do nosso cérebro, ou seja, passamos a pensar analiticamente (PREDEBON, 2005). Com o tempo, passamos a julgar tudo que é "diferente" como errado, pois crescemos fazendo "daquele jeito" e não podemos simplesmente parar e começar a realizar "do outro jeito". Da mesma forma, quando crianças, utilizamos nossa imaginação quase que o tempo inteiro, com perguntas e suposições para as coisas naturais do dia a dia. Porém, durante nosso crescimento somos ensinados que o questionamento é errado e as suposições não são bem aceitas, o que nos deixa acomodados com o "natural" e com a maneira "correta" de se realizar as coisas.

Utilizar o lado esquerdo do cérebro juntamente com o lado direito se torna uma prática saudável na vida. Pessoas que criam diariamente sentem prazer no que fazem, pois liberam a tensão e o estresse do dia a dia, obtendo a satisfação de imaginar coisas novas e utilizar o seu potencial criativo para pequenas tarefas diárias.

Embora a criatividade seja algo natural do ser humano, a maior parte da população não utiliza seu potencial e muitos acreditam que não são suficientemente capazes de possuir ideias criativas. Geralmente, pessoas inovadoras possuem um perfil, ou seja, uma série de características que facilitam a abertura da mente para se obter novas ideias.

Talvez um dos conceitos que desmistifique a personalidade criativa como sendo habilidade de poucos, são as categorias de Gerber (2009). Em sua busca pelo entendimento do espírito empreendedor, esbarrou em pessoas que, independente da função operacional ou gerencial, utilizavam a criatividade de maneira eficaz na solução de problemas.

A maioria dos criativos possui certo grau de independência e uma confiança em si mesmo maior do que as outras pessoas, o que os torna inquietos e proativos. Dessa maneira, 
não é necessário que alguém lhes diga o tempo todo o que deve ser feito; a pessoa criativa possui iniciativa e ousadia nos momentos em que deve desenvolver uma tarefa.

Pessoas que tem a habilidade de tomar iniciativas possuem curiosidade suficiente para saber o que está ocorrendo à sua volta. Essa é uma característica inata, utilizada naturalmente na infância, quando tudo é questionado, todas as coisas são novas e devem ter um "por que".

\begin{abstract}
A curiosidade é o que lhe predispõe a investigar novas áreas ou a procurar uma maneira melhor de fazer algo. A curiosidade direciona o seu ímpeto de criar, experimentar e constituir (MIRSHAWKA JÚNIOR; MIRSHAWKA, 2003, p. 39).
\end{abstract}

Quando se tem curiosidade e ousadia conseguimos facilmente possuir mais uma característica de pessoas criativas: a flexibilidade, que nada mais é do que a habilidade de repensar valores e relativizar o pensamento. Ao vermos um copo com metade de água podemos dizer que ele está meio cheio, mas podemos observar por outro ponto de vista e ver que ele está meio vazio. “Ao aceitarmos essa concepção de mundo, assumimos a convicção de que 'nossa verdade' é apenas 'uma verdade' entre muitas” (PREDEBON, 2005, p. 81).

Quando uma pessoa possui flexibilidade, ela consegue ver um fato de diversos ângulos e o que muitas vezes poderia ser algo ruim é visto como uma oportunidade ou, pelo menos, consegue ser avistado como algo não tão ruim. O poder de ver o lado bom das coisas é também chamado de leveza e pode ser relacionado com o otimismo. Ser leve mostra que a pessoa possui bom humor para as situações cotidianas e faz com se viva de forma mais jovial, observando o mundo de uma forma menos regrada.

Segundo Predebon (2005), costumamos ver lugares, objetos e pessoas muito rapidamente, o que faz com que coisas conhecidas e rotineiras passem despercebidas aos nossos olhos; é como se ocorresse um déjà-vu imaginário. Porém, quando estamos fora da nossa rotina, como em uma viagem, pequenas coisas são vistas e tudo é analisado. Perceber nosso dia, que aos olhos dos outros é comum e muitas vezes não é "enxergado", se chama sensibilidade. Algumas pessoas possuem uma sensibilidade mais apurada que o restante da sociedade e acabam tornando-se mais criativos por "ver" o que muita gente não percebe.

Uma boa ideia só é realmente criativa quando ela é única, ou seja, ninguém é criativo imitando o que os outros já fizeram. Por isso é necessário que se esteja informado sobre o que está acontecendo no mundo. Isso se chama articulação. Um político, por exemplo, não pode saber apenas sobre política, pois é preciso que ele saiba o que está havendo na sociedade para que se crie em cima das necessidades da população. Dessa forma, a pessoa criativa deve estar 
informada sobre diversos assuntos para que, assim, consiga criar algo novo e útil para a sociedade.

Tudo faz crer que, no futuro, realizações significativas e duradouras não virão de pessoas extraordinárias, mas de extraordinárias combinações de pessoas que aprendem a pensar e a trabalhar juntas (MIRSHAWKA JÚNIOR; MIRSHAWKA, 2003, p. 125).

Uma pessoa criativa tem boas ideias, porém, várias pessoas criativas pensando uma mesma ideia torna o projeto colaborativo, ou seja, é necessário aproveitar os talentos e a diversidade em um grupo de trabalho para tornar uma ideia ainda mais criativa. Pessoas que colaboram reconhecem que o seu ponto de vista não é o suficiente para tornar algo realidade; é preciso conhecer e entender a perspectiva de outras pessoas e, assim, tornar o processo uma "criação conjunta".

Steven Johnson (2011) exemplifica isso com um caso do final dos anos 1870, onde Stéphane Tarnier, um obstetra parisiense, visitou um zoológico de Paris. Em um jardim clássico do Zoo, Tarnier se deparou com galinhas chocadeiras e pequenos pintos recémnascidos saindo da casca do ovo, cambaleando pela chocadeira gelada e, no mesmo instante, associou-os aos bebês que nasciam na maternidade, os quais $66 \%$ dos que nasciam abaixo do peso faleciam em semanas após o nascimento porque a regulagem da temperatura era decisiva para manter as crianças vivas. Pensando nisso, ele contratou Odile Martin, que cuidava da criação das aves do zoo e, juntos, eles criaram a primeira incubadora para recém-nascidos. Esse caso mostra que a criação conjunta é muito mais eficiente do que uma ideia criada apenas por uma pessoa. Além disso, a incubadora não foi o primeiro equipamento utilizado para aquecer bebês; pelo contrário, foi necessário aprimorar a ideia do aquecimento e buscar a ajuda de outras pessoas para que o equipamento fosse criado.

$\mathrm{O}$ caso da incubadora nos faz lembrar que uma ideia criativa não nasce em segundos $\mathrm{e}$ que é necessário tempo para que ideias amadureçam, sejam transformadas, ajustadas, compartilhadas e aí, quem sabe, vire uma ideia criativa. "Não há chaves, não há fórmulas para ativar nosso lado criativo. Se existir um segredo, este será particular a cada pessoa e só poderá ser descoberto por ela mesma, com a prática” (PREDEBON, 2005, p. 58).

Esse tempo de maturação necessário, sendo ele duradouro ou explosivo, é o tempo imprescindível para que o Processo Criativo ocorra. Até então, percebemos o quão amplo é o conceito de criatividade e sua relação com a sociedade. Determinadas características deste tipo de pensamento cognitivo irão contribuir para a consolidação do campo da Economia 
Criativa, porém, outras serão conflitantes. É necessário refletir sobre o processo para perceber uma organização sistêmica que equalize o caos para construção de um sentido de economia nessa área.

\section{PROCESSO CRIATIVO}

Nenhuma ideia toma forma de uma hora para a outra. Existe uma série de processos que ocorrem na mente de uma pessoa durante a criação de algo novo. Entretanto, o pensamento criativo só pode surgir se há o desejo de se obter algo novo, e é a aspiração que torna nosso cérebro capaz de trabalhar em busca de uma boa ideia. De acordo com Predebon (2005), o raciocínio lógico age de forma contrária ao raciocínio criativo, portanto, só tem como pensar criativamente quando se tem uma força motivadora buscando isso.

Assim que se tem o desejo de obter algo novo ou a solução de algo, é necessário entender o problema a ser resolvido e buscar todo o tipo de conhecimento sobre esse assunto, o que já se sabe e o que já se criou na área. A incessante busca questionadora já foi citada anteriormente, e se torna cerne do processo e, também, da discussão acerca da relação entre o processo criativo e o sistema de Economia Criativa. Esse processo, conhecido como Preparação, busca mapear o tema em busca de informações que possam servir posteriormente no desenvolvimento de ideias.

É imprescindível analisar o que se descobriu, voltando e observando o que foi feito. É vital saber reconhecer e eventualmente transformar o projeto, o modelo ou o objeto elaborado, inventando ou nele introduzindo novos aspectos ou conexões (MIRSHAWKA JÚNIOR; MIRSHAWKA, 2003, p. 87).

Dessa forma todos os dados pesquisados devem ser avaliados e questionados, numa etapa chamada de Manipulação. Em algumas situações é necessário buscar mais dados sobre o assunto para que possa ser dado andamento no processo.

Predebon (2005) e Mirshawka Júnior e Mirshawka (2003) afirmam que no meio do processo do pensamento criativo é necessário fazer uma pausa, a qual chama-se Incubação. É o momento em que todos os dados são processados pelo inconsciente para uso futuro, para a inspiração. Depois da incubação o cérebro começa a criar diversas possíveis soluções para o problema, como uma "chuva de ideias"; e todas devem ser analisadas antes de serem descartadas porque não se tem uma resposta exata ainda. A fase do Esquentamento é como 
um brainstorm; todas as ideias são bem vindas. Segundo Predebon, em criatividade é necessário trabalhar com quantidade para obter a qualidade.

É natural que quando se possui diversas ideias para resolver determinado problema o resultado apareça. Algumas vezes, a escolha da ideia é resultado da soma de dois ou mais palpites do esquentamento. A Iluminação é a solução do problema, ou seja, todos os processos anteriores foram completos com sucesso e a "chuva de ideias" resultou em uma resposta relevante.

Ao obter a solução de um problema é necessário que a ideia seja verificada, pois, como falado anteriormente, nem todas elas são relevantes para serem utilizadas e muitas ideias já foram pensadas por outras pessoas. Se todas as etapas anteriores tiverem sido cumpridas da maneira correta, as chances da ideia ser relevante são maiores e tem mais oportunidades de saírem do papel.

O processo criativo é composto por etapas simplificadas como as citadas anteriormente. Em sua formação básica é necessário um problema, uma preparação, um trabalho mental e um resultado, seja satisfatório ou não nesse ponto do processo cognitivo. É interessante perceber que um processo tão simples é tão complexo, dada a natureza e o seu relacionamento com a cognição humana.

Esse processo é a base de valor para sustentação de um setor econômico que hoje aparece como tendência mundial. A criação é um fator evolutivo da sociedade (JOHNSON, 2011); é esse processo que mantém e sustenta a forma contemporânea de mundo que temos hoje. Um incessante moinho que se renova sempre que necessário e a uma velocidade cada vez maior. Segundo Geoffrey West (2011), a velocidade das soluções acarretadas pela necessidade de resoluções de problemas nas cidades é exponencialmente maior que a própria constante necessária para manutenção de um organismo, mesmo que social.

Portanto passaremos a abordar a Economia Criativa para relacionar a criatividade e seu processo com a construção sólida de bases organizativas que permitem sustentar uma possibilidade econômica para movimentação financeira de setores, cidades e países. Criar é possível e necessário para evolução social, financeira e para a equalização de um sistema complexo com a vida em sociedade.

\section{ECONOMIA CRIATIVA}

A Indústria Criativa, desde as últimas duas décadas, vem recebendo atenção especial de governos, universidades e indústrias no exterior (DCMS, 1998; DCA, 1994). No Brasil, 
apenas no final da década passada isso se tornou evidente. Segundo Howkins (2007), o aumento expressivo do consumo de bens relacionados ao topo da pirâmide de Maslow é um indicador de mudança de comportamento e do potencial que os setores criativos têm no mercado atual.

Enquanto uma busca frequente de inovação ocorre nos processos, na percepção material da inovação, existe um potencial que agora se torna claro, na construção de imagem da Indústria Criativa. O Manual de Oslo (OCDE, 1997), em sua terceira edição, aborda o Marketing como inovação; mas o conceito na Economia Criativa seria a capacidade da narrativa carregar o DNA da inovação, evoluindo para a intangibilidade criativa.

Não são apenas as narrativas e conteúdos que se tornam intangíveis nesse processo. As ideias de inovação de produto, serviço e processo se tornam moedas no estatuto da economia criativa. "Imagine se a roda fosse patenteada", disse Maurício Moraes (2012), Jornalista da revista INFO, na edição de setembro de 2012. A economia criativa passa ser o ato de agregar valor a uma ideia, ainda em seu formato de intangibilidade. Pensamos, criamos e registramos, esse é o mantra desse processo.

Administração, Economia e Direito ganham um espaço evidente na organização dos processos que regulamentam todo esse mercado. Sob o olhar de um consumidor, um produto representa lucro à empresa produtora. Porém, nesse sistema, inúmeros royalties são pagos a diversos "criadores" de soluções para a possibilidade de produção de um dispositivo. Segundo o Relatório sobre o Iphone (THOMSON REUTERS, 2012), existem 1298 patentes registradas para esse dispositivo. Para perceber o nível de detalhamento das ideias, a forma de destravar a tela inicial do telefone é uma das patentes registradas pela Apple ${ }^{1}$.

Em um sistema que o registro das ideias é levado ao limite, como o processo criativo pode ocorrer? Países como o Brasil, onde o sistema de patentes não permite alguns formatos de registro, nos fazem questionar nossa competitividade mundial. Essas evidências nos fazem pensar nas possibilidades que teremos nos próximos anos. É nesse caminho que a pesquisa mostra sua necessidade. Teríamos então que, nas condições que temos hoje no cenário brasileiro, apostar em uma possibilidade da economia criativa com base na criação de conteúdo? E regionalmente, como estamos preparados?

Aparentemente, quando se fala sobre Economia Criativa, escutamos pessoas que dizem: "São aqueles que trabalham com jogos, publicidade, design, moda e outras coisas assim... criativas!”. É interessante perceber que a Economia Criativa possui duas dimensões

\footnotetext{
${ }^{1}$ A patente que refere-se ao destravar deslizando o dedo foi invalidada pela Corte Judicial Alemã (SIN, 2013).
} 
que a sustenta: a dimensão econômica, que pressupõe um sistema organizado de geração e agregação de valor, que demanda um procedimento sistêmico, muitas vezes visto como incompatível ao processo criativo; e a dimensão criativa, que se sobressai no encantamento, mas não idealiza o conceito se não estiver intrinsicamente ligada a anterior.

Só será considerado um produto ou um serviço criativo se, após o processo de sua criação, ocorrer um procedimento de registro que permita a valorização deste. Através deste procedimento, a situação econômica da ideia é potencializada para economia. A ideia pode ser produzida, vendida, arrecadar royalties de seu uso por terceiros, entre outros formatos de modelos de negócios (HOWKINS, 2007).

É importante partir de uma base de questionamentos que envolva Indústria, Universidade e Governo, assim como o conceito da Hélice Tripla de Henry Etzkowitz, para que possamos aprofundar e entender como estas partes são apropriadas, e de uma forma ampla, como isso se apresenta a sociedade. Segundo Reis e Kageyama (2011), inúmeras cidades hoje se denominam cidades criativas, ou polos de economia criativa.

O olhar da sociedade sobre um fenômeno recente e encantador, é impregnado não apenas pela forma como o desenvolvimento regional (Estado) apresenta seus produtos, processos, serviços, organização e marketing (OCDE, 1997), mas, também, por como esses mesmos atores de outras fronteiras (países) acabam apresentando em nossa região seus produtos de economia criativa, nos infringindo uma percepção de desenvolvimento acobertada pelo paradigma do usuário, ou seja, acreditamos num estado com um alto grau de economia criativa, ou somos apenas usuários das ideias dos outros? Hoje governos como o do Canadá investem fortemente nos setores de Economia Criativa do país, por diversas razões, mas, aparentemente, um resultado eficaz da qualidade do investimento nesses produtos é a multinacionalização de marcas e franquias, assim como os americanos nos anos 1980 e 1990 expandiram sua cultura. Uma parte significativa dos desenhos animados que passam nos canais infantis é produzida pelo Canadá. Portanto, é importante entendermos as experiências exercidas em outras cidades, regiões e países, para percebermos se estamos produzindo ou assimilando, gerando ou gastando. Contudo, de fato, estamos preparados para crescer em um mercado que tem perspectivas, mas, em que outros já estão com um longo caminho percorrido? 


\section{CONSIDERAÇÕES FINAIS}

A relação entre processo criativo e economia criativa é clara, porém, ao invés do sentimento de mutualismo, de promover o crescimento e as trocas benéficas entre os conceitos, podemos perceber uma tendência "canibal" no relacionamento. Enquanto a Economia Criativa avança para uma organização que promove o crescimento e a consolidação financeira, bem como, o respeito à propriedade intelectual, ela também parece colaborar com a saturação do registro de ideias.

Apesar de toda riqueza incutida em um processo politicamente correto de formalização e recompensa do criativo, acaba sendo estabelecida uma barreira processual burocrática para novos processos criativos (LESSIG, 2007). Ao criar, recombinar ou inovar, o criativo esbarra em todo formalismo econômico e administrativo que a área traz consigo. "A maneira mais rápida de congelar uma rede líquida é meter as pessoas em salas individuais por trás de portas fechadas" (JOHNSON, 2011, p. 56)

Não é o principal julgar o valor deste problema, mas perceber que existe um componente que está solidificando, fechando portas em uma rede que apresenta possibilidades de epifanias líquidas (JOHNSON, 2011). Isso irá apresentar novas características no processo de economia criativa nos próximos anos.

A proteção de ideias em um nível elevado acarreta na dificuldade de novos processos criativos. Competir com indústrias criativas de setores sistêmicos como inovações em engenharias e na área de equipamentos eletrônicos é uma tarefa árdua. Em um artigo para o Jornal Brasil Econômico, Melito afirma que: "Destinar recursos para inovação em mercados protegidos é chover no molhado. Talvez esses recursos fossem melhor aproveitados se destinados a sanar gargalos de infraestrutura" (2013, p. 21). Portanto, uma reflexão possível a partir deste panorama é ter como perspectiva de desenvolvimento em economia criativa, setores que possibilitem criação autoral, justamente o desenvolvimento de estórias, narrativas e personagens. Esse tipo de processo gera produtos da natureza de conteúdo, como livros, quadrinhos, música, espetáculos, filmes, jogos digitais e outros. A natureza deste tipo de processo, por ser oriunda de uma base narrativa, dificilmente encontra barreiras intransponíveis da dimensão do registro de ideias. O tipo de conteúdo produzido permite uma disseminação e capilaridade, enquanto franquia, para uma gama de produtos que podem ser introduzidos no mercado. O processo de geração de valor agregado a uma ideia advinda de criação autoral de conteúdo estabelece um patamar competitivo sem objeções legais (afora outras narrativas existentes). 
A natureza do ato criativo permite a todos que estabeleçam novos formatos para solucionar problemas que a própria consolidação desse setor acarreta. Mas, ao mesmo tempo em que nossos setores criativos brasileiros correm para busca de seu desenvolvimento, também temos que estabelecer infraestrutura e políticas balizadoras para o crescimento. E, ainda, concomitante com tudo isto, é importante um olhar analítico sobre os rumos de nossos processos, sejam eles de ordem criativa ou econômica.

Este ensaio teve como função relacionar o processo criativo e a economia criativa a partir de características comuns que podem ou não facilitar a criação. A complexificação do valor do ato criativo, do seu processo e de metodologias é o custo que nos próximos anos iremos pagar. A economia criativa nos cobra, agora, algo que devemos entender como um mutualismo evolutivo. Enquanto percebemos setores não criativos (como se pudessem existir assim) valorizarem em sua organização as novas ideias, iremos ver, também, os ditos setores criativos, conhecidos pelo processo "tumultuado", se tornarem cada vez mais sistêmicos, operacionais e protegidos no campo das ideias.

Devemos entender que o processo criativo mudou? Não cremos nessa hipótese, mas, sim, que o sistema que abrange a consolidação das ideias deste processo está em metamorfose. Empresas, Governos e Universidades estão acompanhando, registrando e criando novas formas de perceber e realizar oportunidades de negócios nos campos criativos que crescem financeiramente.

\section{REFERÊNCIAS}

BACHELARD, G. El Aire y los Sueños - Ensayo sobre a imaginação do movimento. México, D.F: Fondo de Cultura Económica, 1993. ISBN 968-16-4178-7.

BODEN, M. La Mente Criativa - mitos y mecanismos. Barcelona: Edisa, 1994.

DCA. Creative nation: Commonwealth cultural policy, October 1994. Commonwealth of Australia, 1994. Disponivel em: <http://pandora.nla.gov.au/pan/21336/200310110000/www.nla.gov.au/creative.nation/contents.html>. Acesso em: 4 Mar. 2013.

DCMS. Creative Industries Mapping Document. Department for Culture, Media and Sport, 1998. Disponivel em:

<http://www.culture.gov.uk/global/publications/archive_1998/Creative_Industries_Mapping_ Document_1998>. Acesso em: 3 Mar. 2013.

DELEUZE, G. O que é Filosofia? São Paulo: ED 34, 1992. 
GERBER, M. The E Mith. Kindle Edition. ed. [S.1.]: HarperCollins e-books, 2009.

HOWKINS, J. The Creative Economy. Kindle Edition: Penguin Group, 2007.

JOHNSON, S. De onde vêm as boas ideias. Rio de Janeiro: Zahar, 2011.

JUNG, C. G. Tipos psicológicos. Petrópolis: Vozes, 1991. (Obras selecionadas v.VI).

LESSIG, L. Laws that choke creativity. TED: Ideas worth spreading, Março 2007.

Disponivel em:

$<$ http://www.ted.com/talks/larry_lessig_says_the_law_is_strangling_creativity.html $>$. Acesso em: 5 Março 2013.

MARINA, J.A. Teoría de la Inteligencia Creadora. Barcelona: Anagrama, 1993.

MELITO, A. M. Incentivo à Inovação: mais do mesmo. Valor Econômico, São Paulo, 4 Março 2013. 21.

MINC. Plano da Secretaria da Economia Criativa: políticas, diretrizes e ações, 2011-2014. 1. ed. Brasília: Minc, 2011. 148 p. ISBN 978-85-60618-03-3.

MIRSHAWKA JÚNIOR, V.; MIRSHAWKA, V. Qualidade da criatividade. São Paulo: DVS Editora, 2003. 299 p.

MORAES, M. É preciso reinventar a roda? INFO, São Paulo, n. 320, 2012.

OCDE. Manual de Oslo: Diretrizes para Coleta e Interpretação de Dados sobre Inovação. 3. ed. [S.1.]: [s.n.], 1997. 184 p.

PREDEBON, J. Criatividade: abrindo o lado inovador da mente: um caminho para o exercício prático dessa potencialidade esquecida ou reprimida quando deixamos de ser crianças. 6. ed. São Paulo: Atlas, 2005. 248 p.

REIS, A. C. F.; KAGEYAMA, P. Cidades Criativas: perspectivas. São Paulo: Garimpo de Soluções, 2011.

SEI. Bahia Análise \& Dados. Salvador: [s.n.], v. 23, 2013.

SIN, B. German court invalidates Apple's slide-to-unlock patent. Slash Gear, 6 Abril 2013. Disponivel em: $<$ http://www.slashgear.com/german-court-invalidates-apples-slide-to-unlockpatent-06276735/>. Acesso em: 6 Abril 2013.

THOMSON REUTERS. Inside the iPhone patent portfolio: data offers glimpse of batteryfree future, insight into smartphone "Patent Wars". [S.1.], 2012. 
WEST, G. The surprising math of cities and corporations. TED, Julho 2011. Disponivel em:

$<$ http://www.ted.com/talks/geoffrey_west_the_surprising_math_of_cities_and_corporations.h tml>. Acesso em: 28 mar. 2013.

Original recebido em: 03/10/2013

Aceito para publicação em: 20/08/2014

Sobre os autores

Cristiano Max Pereira Pinheiro Doutor em Comunicação Social pela PUCRS; coordenador dos Cursos de Jornalismo, Relações Públicas e

Publicidade e Propaganda e professor do Mestrado em Indústria Criativa da Universidade Feevale.

Francisco Eduardo Menezes Martins

Doutor em Ciencias de la Información Periodismo pela Universidad Complutense de Madrid, Espanha; professor do Mestrado em Indústria Criativa da Universidade Feevale.

Mauricio Barth

Mestrando em Indústria Criativa; bolsista de Desenvolvimento

Tecnológico Industrial do CNPq. 